\title{
Study of Thyroid Profile in Ante-Natal Women: A Hospital Based Prospective Study
}

\author{
Shilpa Tholia ${ }^{1}$, Shweta Chaudhary ${ }^{2}$, Neeta Bindal ${ }^{3}$, Neelam Sood ${ }^{4}$, Syed Nawaz Ahmad ${ }^{1}$ \\ 1Senior Resident, ${ }^{3}$ SAG Officer, Department of Obstetrics \& Gynaecology, \\ ${ }^{4}$ M.D, Department of Pathology, HOD, Deen Dayal Upadhyay Hospital, New Delhi, India. \\ ${ }^{2}$ Assistant Professor, Department of Obstetrics \& Gynaecology, S. P. Medical College, Bikaner, Rajasthan, India
}

\begin{abstract}
Background: Pregnancy is a state in which combinations of events occur and modify the thyroidal economy. Also, thyroid diseases often occur in young adults, with female predominance. Up to $5-10 \%$ of females of child bearing age group may suffer from thyroid dysfunction or presence of thyroid antibodies.
\end{abstract}

Aims \& Objectives: To determine the prevalence of thyroid disorders in pregnant women attending Outpatient department in tertiary care centre.

Material \& Methods: This prospective study was conducted in the department of Obstetrics and Gynaecology Deen Dayal Upadhyay Hospital, a tertiary care multi-speciality government hospital. Screening was done in all antenatal patients by performing thyroid function tests. Thyroid function tests were evaluated by Access 2 immunoassay system by chemiluminiscence method. Goal of therapy was to maintain TSH less than $2.5 \mathrm{mlU} / \mathrm{ml}$ in first trimester and less than 3 $\mathrm{mlU} / \mathrm{ml}$ in second and third trimester. After starting the treatment TSH was repeated after 4weeks- 6 weeks. If serum TSH became normal then serum TSH was repeated 2 monthly. Results: Two hundred women with known last menstrual period and showed only $10 \%$ patients (20/200) were with abnormal thyroid function tests. The mean age of the 200 patients was $23.3 \pm 2.38$ years. In hypothyroid patient $21.1 \%$

\section{INTRODUCTION}

Thyroid disease are known to affect the reproductive health of women, who thus have more miscarriages ${ }^{1}$, anaemia in pregnancy, pre-eclampsia, abruption placenta, post-partum haemorrhage, preterm labour, still birth, gestational hypertension, intrapartum foetal distress. Thyroid dysfunction in pregnant women will also cause increased foetal death rate, low birth weight, increased respiratory distress, neurointellectual child development in their newborn.

Thyroid dysfunction also has a relatively high prevalence during pregnancy, affecting up to $5 \%$ of all pregnant women. ${ }^{2}$ It is known that the foetus is totally dependent on maternal thyroid hormone supply during the first trimester of pregnancy, which is crucial time in organogenesis. ${ }^{3}$ During the first trimester, approximately 1 in 10 pregnant women develop antibodies to Thyroid peroxidase or to Thyroglobulin, and hypothyroidism develops in roughly $16 \%$ of these women. and $1.1 \%$ patient had intra uterine growth restriction $(p<0.001)$ and $10.5 \%$ patient had pre term birth who were hypothyroid $(p<0.001)$.

Conclusion: Our study has demonstrated high prevalence of thyroid disorder and adverse effect on pregnancy. This is suggested that all pregnant women should be screened, so that early diagnosis and treatment could be started even in subclinical form of disease.

Key Words: Hypothyroidism, Pregnancy, Thyroid Function Test.

\section{${ }^{*}$ Correspondence to:}

Dr Shilpa Tholia,

Senior Resident, Department of Obstetrics \& Gynaecology,

Deen Dayal Upadhyay Hospital, New Delhi, India.

\section{Article History:}

Received: 21-06-2016, Revised: 02-07-2016, Accepted: 25-07-2016

\begin{tabular}{|l|c|}
\hline \multicolumn{2}{|c|}{ Access this article online } \\
\hline $\begin{array}{l}\text { Website: } \\
\text { www.ijmrp.com }\end{array}$ & Quick Response code \\
\hline DOI: & \\
10.21276/ijmrp.2016.2.4.026 & \\
\hline
\end{tabular}

The prevalence of hypothyroidism in pregnancy is around $2.5 \%$ according to the western literature. ${ }^{4}$ There are a few reports of prevalence of hypothyroidism during pregnancy from India with prevalence rates ranging from $4.8 \%$ to $11 \% .^{5,6}$

Screening of thyroid function disorder in early gestation can therefore identify those women who carry the risk. Preventive treatment can be administered to avoid the potential deleterious effects of thyroid disorders on both maternal and foetal outcomes. In view of potential for serious adverse events associated with maternal thyroid disease and the apparent benefits of treatment, this study was aimed to estimate the prevalence of the thyroid disorders in pregnant women.

\section{MATERIAL \& METHODS}

This prospective study was conducted in the Department of Obstetrics and Gynaecology, Deen Dayal Upadhyay Hospital, 
a tertiary care multi-speciality government hospital. Prior to the enrolment of first subject in the study clearance from the Ethical and Scientific Committee was taken.

\section{Inclusion Criteria}

1. Pregnant females who attended the antenatal clinic

2. Known last menstrual period

\section{Exclusion Criteria}

1. Known metabolic disorder

2. Known thyroid disorder

3. Known Hypertensive disorder

A detailed history was taken to accurately date the pregnancy, to obtain details of any known metabolic or thyroid disorder or known hypertension and obstetric history, including dietary history.
General and systemic examination is to be done to detect any associated systemic illness. Screening was done in all antenatal patients by performing thyroid function tests. Thyroid function tests were evaluated by Access 2 immunoassay system by chemiluminiscence method. Goal of therapy was to maintain TSH less than $2.5 \mathrm{mlU} / \mathrm{ml}$ in first trimester and less than $3 \mathrm{mlU} / \mathrm{ml}$ in second and third trimester. After starting the treatment TSH was repeated after 4 weeks- 6 weeks. If serum TSH became normal then serum TSH was repeated 2 monthly.

Subjects were followed till 6 weeks postpartum and any complication during pregnancy and outcome of pregnancy and neonatal outcome was noted. TSH was considered normal in first trimester in range of $0.1-2.5 \mu \mathrm{lU} / \mathrm{L}$, second trimester $0.2-3 \mu \mathrm{IU} / \mathrm{L}$ and in third trimester $0.3-3 \mu \mathrm{IU} / \mathrm{L}$.

Table 1: Frequency distribution of the patients as per prevalence of thyroid disorder

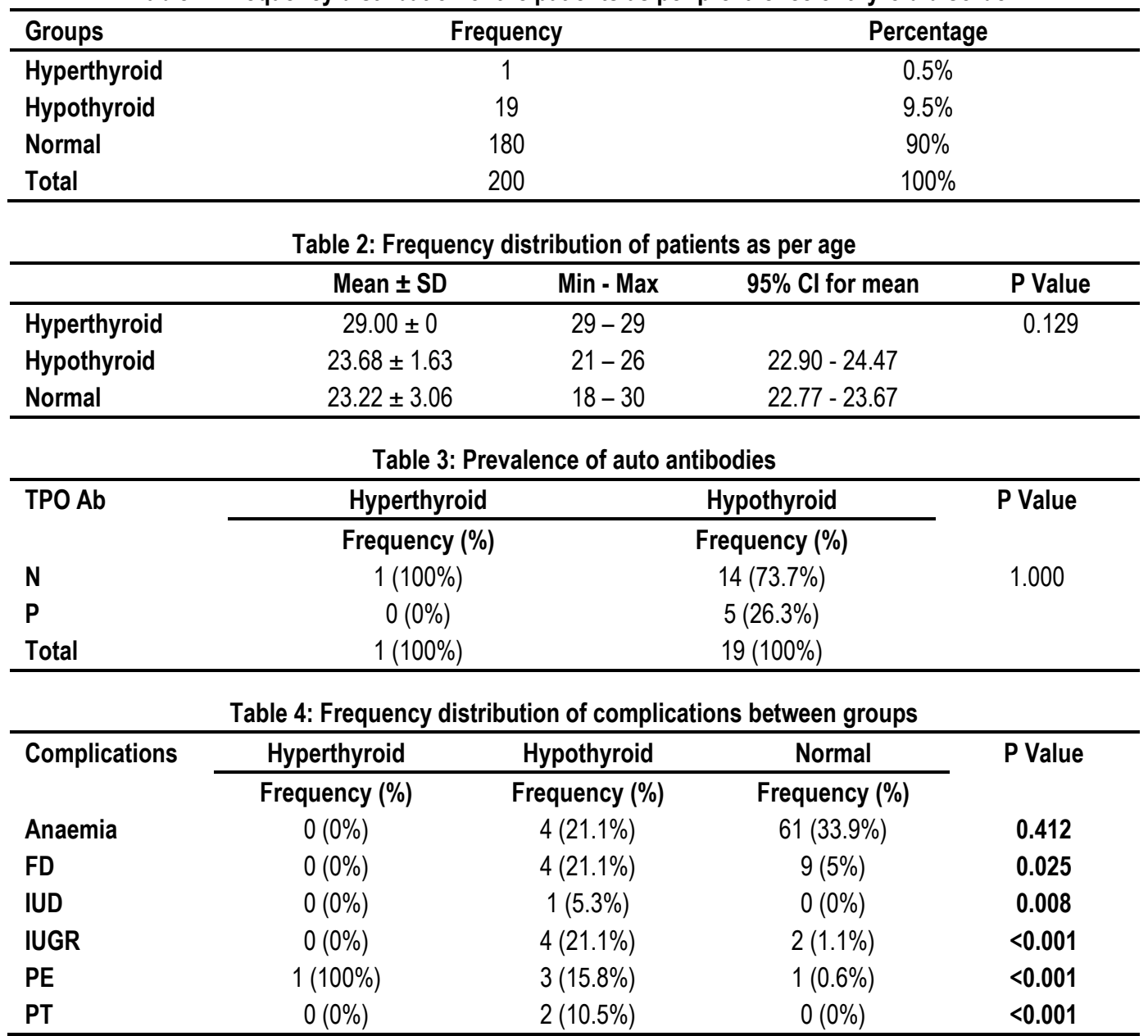

\section{RESULTS}

Two hundred women with known last menstrual period and no known history of thyroid and metabolic disorders attending antenatal clinic of Deen Dayal Upadhyay Hospital were included. Thyroid function tests were done in all these women and showed only $10 \%$ patients $(20 / 200)$ were with abnormal thyroid function tests (table 1). The mean age of the 200 patients was $23.3 \pm 2.38$ years (table 2). Among hypothyroid patients $26 \%$ were anti thyroid peroxidase antibodies positive. Hyperthyroid patient was not positive for thyroid auto antibodies (table 3). In hypothyroid patient $21.1 \%$ and $1.1 \%$ patient had intra uterine growth restriction $(p<0.001)$ and $10.5 \%$ patient had pre term birth who were hypothyroid $(p<0.001)$ (table 4$)$.

\section{DISCUSSION}

Hypothyroidism as well as hyperthyroidism during pregnancy has adverse effects on pregnancy and foetus. Thyroid disorders commonly affect women of reproductive age group hence it makes sense to screen pregnant women for thyroid disorders, more so because of the effect it can have on the neurological and structural development of the foetus if the patient remains untreated.

In developing countries like India where resources are limited, the question of universal screening might appear to be unfeasible. To evaluate the cost effectiveness of any screening protocol it is important to know the impact of that particular disorder in the region. 
In our study we included 200 patients, out of these $54.5 \%$ women were in the 18-23 year age group. Nambiar $V$ et al ${ }^{5}$ (2011) also studied the prevalence and impact of thyroid disorder in 583 women. The mean age of women was $25.19 \pm 4.17$ years which was almost similar to our study.

In our study prevalence of thyroid disorder in antenatal woman was $10 \%$. Out of 200 women, 19 had serum TSH above the trimester specific reference range. None of woman had overt hypothyroidism. In the study done by Agarwal $\mathrm{N}$ et $\mathrm{al}^{9}$, high prevalence of clinical hypothyroidism (10.9\%) was seen, which correlates well with our study. However the study by Nambiar $V$ et $a^{5}$ showed $4.8 \%$ prevalence of hypothyroidism. Another study done by Saki $\mathrm{F}$ et al $^{7}$ also reported $11.3 \%$ subclinical hypothyroidism which is almost similar to our study. Gayatri et al ${ }^{8}$ found $2.8 \%$ subclinical hypothyroidism in pregnant women. Differences in comparison may be due to different laboratory methods, kits and difference in normal trimester specific reference range used in different studies.

In our study $26.1 \%$ patients having hypothyroidism were anti TPO antibody positive while none had anti-thyroglobulin antibodies. In the study done by Agarwal $\mathrm{N}$ et al, ${ }^{9} 57 \%$ were positive for antithyroid peroxidase antibodies. These findings suggest that auto immunity is the main etiology of hypothyroidism. These finding are supported by the study done by Gayathri et al. ${ }^{8}$ Their study showed that $57.1 \%$ patients were anti thyroid peroxidase antibody positive.

The prevalence of IUD came out to be $5.26 \% \quad(p=0.008)$, intra uterine growth restriction is $21.1 \%(p<0.001)$, pre-eclampsia 15.8 $\% \quad(p<0.001)$, preterm deliveries $5.26 \% \quad(p<.001)$. The complications were statistically significant. Study done by Saki $F$ et $\mathrm{al}^{7}$ also supported our results. They found that prevalence of pre-eclampsia was $6.3 \%$, prevalence of preterm was $11.3 \%$ in patients who had subclinical hypothyroidism.

Wilson $\mathrm{KL}$ et al10 concluded that subclinical hypothyroidism and severe pre-eclampsia had significant association. Chen LM et al11 found that prevalence of subclinical hypothyroidism was $4.63 \%$ and incidence of IUGR was (2.96\%). Saki $\mathrm{F}$ et al ${ }^{7}$ detected intra uterine growth restriction in $7.8 \%$ and increased risk of fetal distress. Caesarean section was $16.2 \%$ in their study.

In the study done by Sahu $M$ et $a^{6}$ also showed that caesarean rate for fetal distress was significantly higher in women with subclinical hypothyroidism (p0.04) and supports our study results.

\section{CONCLUSION}

The issue of universal screening for thyroid disorder remains controversial. Our study has demonstrated high prevalence of thyroid disorder and adverse effect on pregnancy. This is suggested that all pregnant women should be screened, so that early diagnosis and treatment could be started even in subclinical form of disease. That can prevent adverse effect of thyroid disorders in pregnant women and maternal and fetal outcome could be improved.

\section{REFERENCES}

1. Anselmo J, Cao D, Karrison T, Weiss RE, Refetoff S. Fetal loss associated with excess thyroid hormone exposure. J Am Med Assoc 2004;292(6):691-95.

2. Glinoer D, De NP, Bourdoux P, Lemone M, Robyn C, van Steirteghem A, Kinthaert J, Lejeune B. Regulation of maternal thyroid during pregnancy. J Clin Endocrinol Metab1990; 71(2): 276-87

3. Calvo RM, Jauniaux E, Gulbis B, Asuncion M, Gervy C, Contempre B, Morreale de Escobar $\mathrm{G}$. Fetal tissues are exposed to biologically relevant free thyroxine concentrations during early phases of development. J Clin Endocrinol Metab 2002 Apr;87(4):1768-77.

4. Le Beau So, Mandel SJ. Thyroid disorders during pregnancy. Endocrinol Metab Clin North Am 2006;35: 117-36.

5. Nambiar V, Jagtap VS, Sauthi V, Lila AR, Kamlanathan S, Bandgar TR. Prevalence and impact of thyroid disorders on maternal outcome in AsianIndian pregnant women. J Thyroid Res [Internet]. 2011 Jul [ cited 2011 Jul17]:[about 6 pp].Availablefrom: http://www.ncbi.nlm.nih.gov/pmc larticles/ PMC3140706/

6. Sahu MT, Das V, Mittal S, Agarwal A, Sahu M. Overt and subclinical thyroid dysfunction among Indian pregnant women and its effects on maternal and fetal outcome. Arch Gynecol Obstet 2010; 281:215-20.

7. Saki F, Dabbaghmanesh MH, Ghaemi SZ, Forouhari S, Omrani GR, Bakhshayeshkaram M. Thyroid Function in Pregnancy and Its Influences on Maternal and Fetal Outcomes. Int J Endocrin Metab 2014;12(4). doi:10.5812/ijem.19378.

8. Gayathri R, Lavanya S, Raghavan K. Subclinical hypothyroidism and autoimmune thyroiditis in pregnancy- a study in South Indian subjects. J Assoc Physicians India 2009 Oct; 57:691-3.

9. Aggarwal N, Suri V, Joshi B, Dutta P, Bhansali A, Mukhopadhyay K. Prevalence and impact of subclinical hypothyroidism on pregnancyprospective study from apex institute of North India. Indian J App Res 2014;4(10):404-6.

10. Wilson KL1, Casey BM, McIntire DD, Halvorson LM, Cunningham FG. Subclinical thyroid disease and the incidence of hypertension in pregnancy. Obstet Gynecol. 2012 Feb;119(2):315-20.

11. Chen LM, Du WJ, Dai J, Zhang Q, Si GX, Yang H, Ye E-L, Chen Q-S, Yu L-C, Zhang C, Lu X-M. Effects of Subclinical Hypothyroidism on Maternal and Perinatal Outcomes during Pregnancy: A Single-Center Cohort Study of a Chinese Population. PLoS One. 2014; 9(10). doi:10.1371/journal. pone. 0109364

\section{Source of Support: Nil. Conflict of Interest: None Declared.}

Copyright: ( $)$ the author(s) and publisher. IJMRP is an official publication of Ibn Sina Academy of Medieval Medicine \& Sciences, registered in 2001 under Indian Trusts Act, 1882.

This is an open access article distributed under the terms of the Creative Commons Attribution Non-commercial License, which permits unrestricted non-commercial use, distribution, and reproduction in any medium, provided the original work is properly cited.

Cite this article as: Shilpa Tholia, Shweta Chaudhary, Neeta Bindal, Neelam Sood, Syed Nawaz Ahmad. Study of Thyroid Profile in AnteNatal Women: A Hospital Based Prospective Study. Int J Med Res Prof. 2016; 2(4):111-13. 